\title{
Influence of variability of irrelevant features on concept transfer in children
}

\author{
LORRAINE A. LOW, MARK WOOLVERTON, and ROBERT LUSIGNAN \\ Framingham State College, Framingham Center, Massachusetts 01701
}

\begin{abstract}
Influence of variability of irrelevant information upon concept transfer was investigated in first and fourth graders. Pictures of faces were presented and children placed them into teams based on the shape of the ears. Shape of the eyes and moustache varied and were irrelevant. In acquisition, the MV group had three different moustaches and the MC group had one moustache. In transfer, shapes of moustaches, ears, and eyes were either old or new ones. The task was similar to acquisition but faces with new ears were to be designated "new team." Errors in which faces from the "old team" were called "new" were analyzed. For fourth graders, the MC condition, but not MV, increased errors with the new moustache. For first graders, new moustaches increased errors in both MC and MV conditions. Results supported the hypothesis that older children are differentially influenced by variability of irrelevant stimuli.
\end{abstract}

In a previous study (Low \& Berardi, 1976), children were presented with pictures of faces which differed in the shapes of the eyes, ears, and moustaches. The task was to identify the faces on the basis of the shapes of the ears alone. During transfer the children were required to identify a new ear as well as the old ones; change in the eyes and moustache, both irrelevant to the solution of the problem, resulted in an increase in the number of errors in which the faces with old ears were mistakenly identified as new. Thus, stimuli irrelevant to the solution were important in defining the concept of the face for the child.

Since all irrelevant stimuli do not necessarily become part of the prototype, the question arises as to which irrelevant stimuli are eliminated and which are maintained as part of a concept. It was suggested in that study that irrelevant stimuli which vary will not be considered part of the concept, while those irrelevant features which do not vary will be maintained as part of the concept.

A simple example is one in which a child is asked to discriminate between a triangle and a circle. Let us assume that color is irrelvant to the solution of the problem. If the child is exposed to red, green, and blue triangles and squares, he will learn that color is irrelevant to the solution of the problem. If he is then presented with a black circle, we predict that the concept

The authors thank Ian Goslin, Deborah Langley, and Maureen Tyrell for their help in testing subjects. The authors also wish to thank the administrators, teachers, and students of the following elementary schools in Framingham, Natick, and Marlboro, Massachusetts: Center School, St. Bridget's School, The Immaculate Conception School, and the Johnson School. A portion of this paper was presented at an undergraduate research conference at Brandeis University, Waltham, Massachusetts, 1976. Requests for reprints should be sent to Lorraine A. Low, Psychology Department, Framingham State College, Framingham, Massachusetts 01701. of circle will be maintained and that he will make the appropriate response. However, if another child is exposed to one color, say, a yellow square and a yellow circle, the response to circle or square is similarly a response to the color yellow. The irrelevancy of color lies not in the response to circle or square per se, but in discriminating the difference between circle and square. The former type of irrelevancy is similar to what Homer and Chambliss (1975) refer to as idiosyncratic stimuli and the latter, common stimuli. Thus, irrelevant stimuli which are variable are easier to detect as irrelevant, since they do not enter into the definition of the individual concept nor discriminate among concepts. It is therefore expected that change in irrelevant features would be less detrimental to concept loss if the irrelevant features were varied during acquisition than if they were constant. Similarly, it is expected that older children would be more likely to discriminate variable from constant features and be less responsive to change in variable irrelevant features than to change in constant irrelevant features. Younger children should be equally responsive to change in irrelevant features regardless of variability during acquisition. The present study was designed to test this hypothesis.

\section{METHOD}

\section{Subjects}

The subjects were 50 first graders and 32 fourth graders randomly selected from St. Bridget's School, Framingham; Center School, Natick; Johnson School, Natick; and The Immaculate Conception School, Marlboro. Thirty-six first graders, however, were eliminated because of failure to reach criterion. Therefore, a total of 14 first graders remained and 14 fourth graders were randomly selected from the total of fourth graders tested.

\section{Design}

The first and fourth grades constituted the first betweensubject variable (age). Subjects in each grade were equally divid- 
ed into two groups, the moustaches-constant (MC) and the moustaches-variable (MV) groups. Thus, variability (var) was the second between-subject variable. Within-subject variables occurred during transfer. The first within-subject variable was the presence of old or new moustaches (moustache), and the second was the presence of old or new pairs of eyes (eyes). The design was a 2 (age) by 2 (var) by 2 (moustache) by 2 (eyes) mixed factorial.

\section{Stimulus Material}

The faces were cut-out features of black construction paper pasted on poster board. Three different shapes of ears constituted the relevant dimension and, therefore, the basis of classification. For the MV group, three different shapes of moustaches varied orthogonally with the ears. For the MC group, there was one shape of moustache for all stimuli during acquisition. For both MC and MV groups, there were three different shapes of eyes varying orthogonally with the ears and with the moustaches for the MV group. The MC group was therefore exposed to 9 different faces during acquisition and the MV group to 27 different faces. For the transfer phase, all children were exposed to the same stimuli. Each of the three sets of ears presented during aquisition was presented along with a new set of ears. One of the three sets of eyes presented during acquisition was again presented in transfer (old eyes). In addition, a new set of eyes was presented in transfer (new eyes). The moustache presented to the MC group in acquisition was also used in transfer (old moustache). This moustache was one of three presented to the MV group during acquisition. In addition, there was a new moustache during transfer. Each old or new moustache, old or new pair of eyes, and the four pairs of ears (three old and one new) were orthogonally combined, resulting in 16 different faces randomly assigned to transfer trials. Each face was presented equally often in transfer.

\section{Procedure}

The child was informed that this was a game and that his task was to put the faces into the red, white, or blue team on the basis of a particular facial feature. He was informed about the variability of the facial features. He was told to guess, after seeing each face, to which team it belonged. He was informed of the correct response immediately after his own response. The relevant dimension was the shape of the ears, and the teams corresponded to the different shapes. The child was given 36 acquisition trials in all. For the MV groups the first nine pictures were repeated, since there were 27 stimuli.

For the MC group, there were nine different stimuli, each repeated four times. Only those children who reached the criterion of at least six correct out of the last nine trials in acquisition were included.

In transfer, the child was informed that he would see old and new pictures. If the old or new picture belonged to the Red, White, or Blue team he was to indicate this. If not, he was to respond "New Team." There were 48 transfer trials.

\section{RESULTS}

The number of errors in which stimuli with old ears were placed on the "new team" was the response measure analyzed. This response measure indicated the extent to which change in the irrelevant stimuli resulted in the child's misidentifying the members of the red, white, or blue team as members of the new team. A mixed analysis of variance was performed on the data, with Age and Var as the between-subject variables, and Eyes and Moustache as the within-subject variables. The mean number of errors in the different conditions

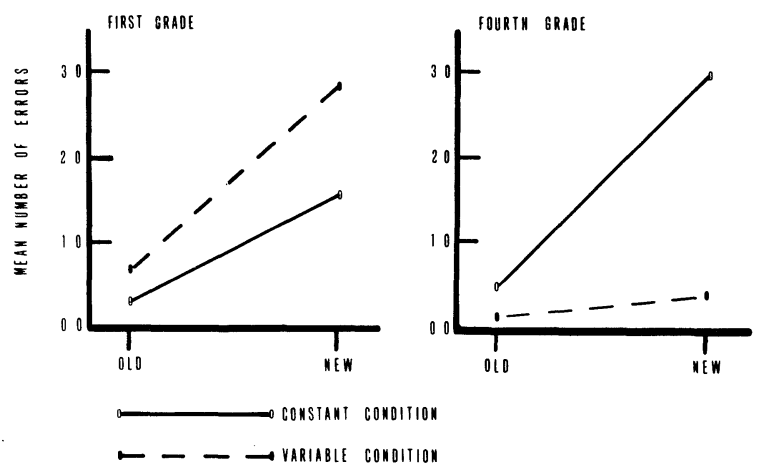

Figure 1. Mean number of errors during transfer resulting from placing faces belonging to Team Red, White, or Blue in the new team for first and fourth graders in Conditions MC and MV with old and new moustaches.

is given in Figure 1. The only significant main effect was that associated with old or new moustache. The mean number of errors for the old moustache was .39 and for the new ones it was $1.98[F(1,24)=20.50, p<.01$, $\mathrm{MSe}=5.82]$. The Age by Var condition was also statisttically significant $[F(1,24)=6.48, p<.05, \mathrm{MSe}=5.82]$. It is evident from inspection of Figure 1 that, for the first graders, the variability served to increase the number of errors in identifying the old ears, while, for the fourth graders, the effect of variability was to diminish the number of errors. The most important significant finding was the Age by Var by Moustaches interaction $[F(1,24)=6.48, p<.05$, MSe $=3.45]$. It is evident from inspection of Figure 1 that, for the first graders, the effect of the new moustache was to increase the number of errors significantly in both the $\mathrm{MC}$ and MV conditions. However, the effect of a new moustache was to increase errors in the MC condition but not in the MV condition for the fourth graders. Thus, the fourth graders were influenced by a new moustache only when the moustache was held constant during acquisition. Since the younger children found the tasks more difficult, as evidenced by the large number who did not reach criterion, analysis was performed on the number of errors in identifying the old faces during transfer. If the younger children were indeed performing more poorly, this would be evidenced in a greater number of errors in transfer on the same task as that in acquisition. A 2 (Age) by 2 (Var) analysis of variance was performed on this error data. However, neither the main effects nor the interaction reached statistical significance.

\section{DISCUSSION}

The results clearly indicate that variability of the irrelevant dimension influences whether or not that dimension will be considered part of the concept. For the fourth graders, the change in the moustache resulted in an increase in errors in correctly identifying the face only when the moustache had been held constant in acquisition. With three moustaches during acquisition, change in the moustache during transfer was disregarded and had no effect on concept identification. 
For the younger children, however, change in the moustache resulted in an increase in number of errors for both the MC and MV conditions. One explanation is that younger children do not process variability as irrelevant and any change is therefore regarded as a change in the concept itself. Alternatively, this might have been too difficult a task for the younger children. Since they had not really identified the concept in the first place, any change would result in concept loss. However, the failure of the errors in identifying the old stimuli during transfer to yield statistically significant differences weakens this argument.

Several variables deserve further exploration. A quantitative relationship between variation and concept loss can be further specified. The extent to which older children make use of the variability of the irrelevant dimension in eliminating the dimension from the definition of the concept needs to be studied further. In addition, in the present experiment facial features were used as stimuli. These stimuli are generally learned as configurations, so irrelevant features would generally be incorporated as part of the prototype. The extent to which variability of irrelevant information for novel configurations influences concept loss is presently under investigation in our laboratory.

\section{REFERENCES}

Homa, D., \& Chambliss, D. The relative contributions of common and distinctive information on the abstraction from ill-defined categories. Journal of Experimental Psychology, 1975, 104, 351-359.

Low, L. A., \& BerARDi, P. Loss of concept identification in children with change in irrelevant facial features. Bulletin of the Psychonomic Society, 1976, 8, 466-468.

(Received for publication July 30, 1976.) 